\title{
Lesiones gastrointestinales en trauma abdominal contuso en niños
}

\author{
Dres. Javiera Aguirre $F^{(1)}$, Lizbet Pérez $M^{(2)}$, Andrés Retamal $C^{(1)}$, Cristian Medina $S^{(1)}$.
}

1. Residente de Radiología, Facultad de Medicina Clínica Alemana - Universidad del Desarrollo. Santiago, Chile.

2. Radióloga, Clínica Alemana de Santiago. Santiago, Chile.

\section{Gastrointestinal injuries from blunt abdominal trauma in children}

\begin{abstract}
Trauma is the leading cause of death in pediatric patients older than 1 year, with abdominal trauma accounting for $10 \%$ of causes of death. Hollow viscera injuries are less than $1 \%$, however its mortality is $20 \%$ in the case of intestinal perforation. Computed tomography is the method of choice for the identification and quantification of abdominal trauma injuries, given its excellent performance for solid viscera injuries, with less sensitivity in hollow visceral injuries, so that in the latter a high clinical suspicion and thorough analysis of the images by radiologists is important. A retrospective review was conducted of the findings in pediatric patients, with a history of blunt abdominal trauma, referred to computed tomography. The main findings on computed tomography suggestive of hollow visceral injury were: extraluminal air, extravasation of contrast medium, the presence of free intraperitoneal fluid, sentinel clot adjacent to the affected loop and thickening of the bowel wall. Keywords: Abdomen, Bruising, Computed tomography, Hollow viscera, Intestine, Pediatrics, Trauma.
\end{abstract}

Resumen: El trauma es la principal causa de muerte en los pacientes pediátricos mayores de 1 año, siendo el trauma abdominal responsable del $10 \%$ de las causas de muerte. Las lesiones de vísceras huecas es inferior al $1 \%$, sin embargo, su mortalidad es del $20 \%$ en el caso de perforación intestinal. La tomografía computada es el método de elección en la identificación y cuantificación de las lesiones en trauma abdominal, dado su excelente rendimiento para lesiones de vísceras sólidas, con menor sensibilidad en lesiones de vísceras huecas, por lo que en estas últimas es importante una alta sospecha clínica y análisis minucioso de las imágenes por parte de los radiólogos. Se realizó una revisión retrospectiva de los hallazgos en pacientes pediátricos referidos a tomografía computarizada, con historia de trauma abdominal contuso. Los principales hallazgos en tomografía computada sugerentes de lesión de víscera hueca fueron: aire extraluminal, extravasación de medio de contraste, presencia de líquido libre intraperitoneal, coágulo centinela adyacente al asa comprometida y engrosamiento de la pared intestinal.

Palabras clave: Abdomen, Contusión, Intestino, Pediatría, Tomografía computarizada, Trauma, Víscera hueca.

Aguirre J, Pérez L, Retamal A, Medina C. Lesiones gastrointestinales en trauma abdominal contuso en niños. Rev Chil Radiol 2014; 20(3): 105-111.

Contacto: Javiera Valentina Aguirre F. / javiera.aguirre.fe@gmail.com

Trabajo recibido el 06 de noviembre de 2013. Aceptado para publicación el 24 de junio de 2014.

\section{Trauma abdominal contuso en pediatría}

El trauma es la principal causa de muerte en los pacientes pediátricos mayores de 1 año, siendo el trauma abdominal responsable del $10 \%$ de las causas de muerte ${ }^{(1)}$. El $90 \%$ son lesiones contusas secundarias a accidentes de tráfico, otras causas menos frecuentes son las actividades recreativas y el maltrato infantil(1). El trauma abdominal representa una amenaza para la supervivencia de la víctima de- bido a mecanismos como la hemorragia por lesión de vasos sanguíneos o de órganos sólidos y la peritonitis secundaria a lesión de vísceras huecas ${ }^{(1)}$.

Las características anatómicas del niño, como un tronco corto y un menor desarrollo osteo-muscular, lo predisponen a una gran variedad de lesiones en el trauma abdominal(2).

Las lesiones de vísceras huecas son infrecuentes y de difícil diagnóstico debido a su baja sospecha y 
hallazgos inespecíficas, sin embargo, conllevan a una alta morbimortalidad. La tomografía computada (TC) es el método de elección en la identificación y cuantificación de las lesiones en trauma abdominal(3), dado su excelente rendimiento para lesiones de vísceras sólidas, con menor sensibilidad en lesiones de vísceras huecas, por lo que en estas últimas es importante una alta sospecha clínica y análisis minucioso de las imágenes por parte de los radiólogos.

El objetivo de nuestro trabajo fue revisar el protocolo de tomografía computarizada utilizado en el estudio del trauma en el abdomen pediátrico.

Para esto se realizó un estudio retrospectivo de selección de casos de lesiones gastrointestinales en tomografía computada de trauma abdominal contuso en niños entre los años 2010 a 2013, realizados en nuestros centros de trabajo.

\section{Protocolo de tomografía computarizada}

La TC es la técnica de elección en el estudio de urgencia del traumatismo en los niños. Tiene una sensibilidad del $85 \%-95 \%$ en las lesiones del tracto gastrointestinal ${ }^{(12)}$. El examen debe ser realizado obteniendo imágenes desde la base del tórax hasta la raíz de los muslos, retirándose los aparatos metálicos de monitoreo del campo en el caso de que los hubiese ya que pudiesen producir artefactos que pudiesen dificultar el correcto diagnóstico(3).

La sedación rara vez es requerida, ya que los tomógrafos actuales requieren de muy poco tiempo para la adquisición de las imágenes ${ }^{(3)}$. La TC helicoidal es alrededor de 10 veces más rápida que la TC convencional, lo cual es de gran utilidad en este tipo de pacientes ${ }^{(12)}$. Dada su gran velocidad el examen se realiza en un solo barrido y permite también que todo el estudio pueda efectuarse en los momentos en que el medio de contraste yodado alcanza su mayor concentración y con ello consigue una mejor opacificación de los órganos estudiados ${ }^{(5)}$.

Una adecuada inmovilización debiera además contribuir en la reducción de artefactos por movimiento ${ }^{(4)}$.

El uso de contraste e.v. es esencial para el estudio del parénquima de los órganos abdominales, así como para la evaluación del sangrado activo. Una dosis de $2 \mathrm{ml} / \mathrm{Kg}$ (máximo de $120 \mathrm{ml}$ en total) es la dosis de elección en estos $\operatorname{casos}^{(3)}$ con un delay de 60-70 segundos. El grosor de corte de 5-6 mm con un pich de $1.5^{(5)}$ y reconstrucciones de $1 \mathrm{~mm}$ permite la adecuada representación de órganos y estructuras $y$ hace posible reconstrucciones multiplanares ${ }^{(12)}$.

El ajuste de kilovoltaje y miliamperaje según edad y peso del paciente debería realizarse según cada caso. Es de responsabilidad del radiólogo y tecnólogo médico el contar con estos protocolos en cada institución según equipos disponibles localmente ${ }^{(6)}$. Existe una relación lineal entre el mAs y la dosis de irradiación. Para esto se dispone de tablas para el cálculo del mAs por kilo de peso y área a estudiar que debiese ajustarse con cada caso. En cuanto al kV, si éste se reduce se baja la dosis, aumenta el ruido y disminuye el contraste de la imagen, pero hay datos que sugieren que un $\mathrm{kV}$ de 80 puede proporcionar una calidad aceptable de la imagen en pacientes pediátricos. En resumen se debe ajustar para obtener una mínima dosis con calidad suficiente que aporte al diagnóstico(6).

El uso de múltiples fases no debería realizarse ${ }^{(4)}$, salvo en casos de lesión en el parénquima renal, una adquisición más tardía es útil para lesiones del sistema excretor y vejiga. Se estima un tiempo de 3 a 5 minutos de retardo para la adquisición de estas imágenes ${ }^{(3,5)}$.

El uso de material de contraste oral es controversial $^{(3)}$ y prácticamente no se administra en nuestro medio, aunque su administración no se asocia con un mayor riesgo de aspiración, la realización de un TC con contraste oral retrasa el diagnóstico y no aporta un incremento de la sensibilidad y de la especificidad para detectar lesiones intraabdominales en relación con la realización únicamente del TC con contraste $\mathrm{IV}^{(3,5)}$.

\section{Causas y mecanismos de injuria gastrointestinal}

Las lesiones gastrointestinales son infrecuentes, con una incidencia menor al $5 \%{ }^{(7)}$, sin embargo, la mayoría de éstas requiere una intervención quirúrgica y la mortalidad en el caso de perforación intestinal es del $20 \%{ }^{(2)}$.

Los accidentes de tránsito constituyen una de las causas más frecuentes de injuria gastrointestinal en niños. En estos casos, fenómenos de rápida aceleracióndeceleración de las estructuras intestinales cercana a su punto de fijación anatómica y compresión del abdomen entre el cinturón de seguridad y la columna vertebral se describen entre los principales mecanis$\operatorname{mos}^{(7,8)}$. El mal uso de los cinturones de seguridad en niños aumenta cuatro veces el riesgo de sufrir lesiones gastrointestinales. Desde el punto de vista clínico, la presencia del "signo del cinturón de seguridad", que se ha descrito como un área de equimosis o abrasión en el abdomen en relación a la zona comprimida por el cinturón de seguridad, se asocia a una probabilidad 13 veces mayor de trauma gastrointestinal( ${ }^{(7)}$. Las lesiones gastrointestinales no son las únicas esperables por este mecanismo; se ha descrito el síndrome del cinturón de seguridad que agrupa lesiones de intestino, mesenterio, estómago, hígado, bazo, fracturas vertebrales tipo Chance y fracturas de la pelvis ${ }^{(2)}$.

Otra causa de lesiones gastrointestinales en niños es el maltrato. En estos casos es frecuente que el cuidador o niño niegan el antecedente de trauma o el mecanismo de trauma referido es desproporcionado y no explican la magnitud de las lesiones encontradas $^{(7)}$. En estos casos los niños por lo general tienen 
una edad promedio de 2-3 años y presentan lesiones de mayor severidad con una tasa de mortalidad que varía de $45-50 \%{ }^{(2)}$. Las lesiones del hígado y bazo son las más frecuentes seguidas por el duodeno, páncreas y riñón ${ }^{(2)}$, siendo las lesiones de vísceras huecas tres veces más frecuentes que en los traumas accidentales ${ }^{(2)}$. Estas lesiones son debidas a la compresión de las vísceras abdominales contra la columna vertebral después de un golpe de puño a patada abdominal ${ }^{(2)}$. Otras lesiones asociadas al maltrato incluyen injurias de tejidos blandos (95\%), trauma craneoencefálico (45\%), fracturas de las extremidades $(27 \%)$ y las fracturas de cráneo $(18 \%)^{(2)}$.

\section{Lesiones del tracto gastrointestinal}

Las manifestaciones clínicas son variadas y dependen del tipo de injuria, van desde contusiones de la pared intestinal, hematomas hasta perforaciones intestinales con extravasación del contenido a la cavidad peritoneal $^{(9)}$.

En el caso de las perforaciones que ocurren en el tracto gastrointestinal proximal (estómago y duodeno), se vierte el contenido a la cavidad peritoneal causando una peritonitis química muy dolorosa que es diagnosticada precozmente ${ }^{(9)}$, mientras que las perforaciones más distales del intestino delgado donde el pH es neutro y hay una baja carga bacteriana ${ }^{(2)}$, son poco sintomáticas inicialmente y tienden a presentarse en forma tardía ${ }^{(10)}$, pudiendo ser diagnosticadas 24 a 48 horas luego del traumatismo inicial debido al desarrollo de peritonitis y/o sepsis de foco abdominal $^{(9)}$, hecho que aumenta la morbilidad y mortalidad en este grupo de pacientes ${ }^{(11)}$. Es por esto que la TC juega un papel importante en la evaluación inicial(8).

Estómago: La rotura gástrica es muy rara con una incidencia de 0,02 a 1,7\% ${ }^{(13)}$. Los accidentes de tránsito son la causa más frecuente, con contusiones directas en el epigastrio que producen aumentos súbitos de la presión intra gástrica. Existe a menudo la historia de una comida reciente, traumatismo en el lado izquierdo del cuerpo y de uso inadecuado del cinturón de seguridad ${ }^{(13)}$. Los sitios más comunes de rotura son la pared anterior y la curvatura menor ${ }^{(13)}$. Se asocian frecuentemente a laceraciones esplénicas $^{(13)}$ (Figura 1).

Figura 1. Niño de 11 años, atropellado en la vía publica. a), b) y c) TC con contraste en fase venosa, cortes axiles a diferentes niveles. Se observa una discontinuidad de la paredes del estómago con sus bordes evertidos (flecas blancas), hay líquido libre intra-abdominal con densidades diferentes (flecas curvas blanca y blanca discontinua), neumoperitoneo anterior (asterisco) y laceraciones esplénicas (flecha negra). d) La laparotomía exploradora confirmó el diagnóstico del estallido gástrico con vaciamiento de su contenido a la cavidad abdominal, laceraciones esplénicas. Se realizó una rafia de las paredes del estómago y aseo de la cavidad abdominal.
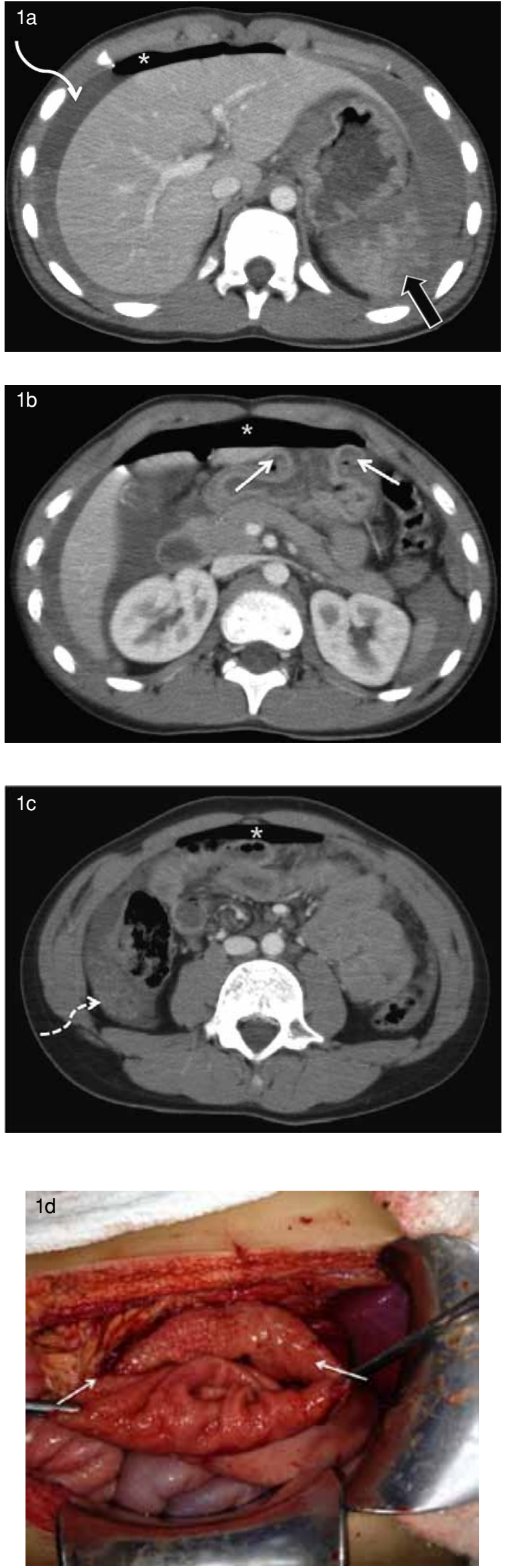
Duodeno: La ubicación retroperitoneal del duodeno le proporciona protección, por lo que se necesitan fuerzas significativas para causar lesiones ${ }^{(7)}$. Las lesiones del duodeno son infrecuentes; en niños representan el 2 a $3 \%$ de las lesiones en traumas abdominales contusos $^{(14)}$ y son marcadores de abuso infantil en niños menores de 2 años cuando se diagnostican en ausencia de trauma grave ${ }^{(7)}$. Se presentan en dos formas: hematoma y perforación (2) (Figura 2).

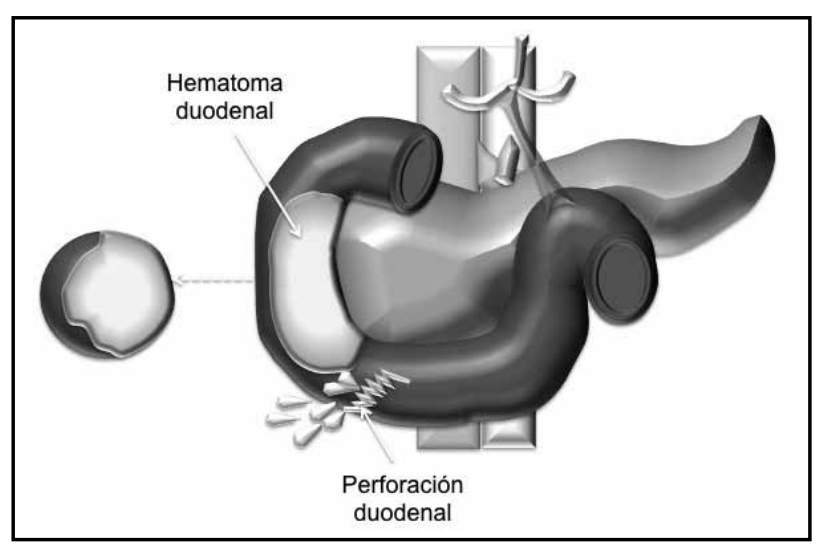

Figura 2. Dibujo de las principales lesiones del duodeno, el hematoma duodenal es una aerea ovalada de acumulación de contraste que protruye hacia el lumen intestinal disminuyendo su calibre, mientras que la perforación de duodeno puede observarse como una zona de discontinuidad de la pared y/o extravazación de contraste.

La mayoría de los hematomas duodenales son submucosos, pero pueden también ser subserosos e intramusculares ${ }^{(14)}$. Los hematomas resultan de la acumulación de sangre intramural secundario a la rotura de los vasos entre la capa submucosa y la muscular, favorecido por la presencia de ricos plexos vasculares submucosos y subserosos y por la distinta distensibilidad de las tres capas de la pared que lo predisponen al desarrollo de hematomas intramurales ante traumas abdominales cerrados ${ }^{(14)}$. Estos comprometen la pared lateral duodenal, siendo la segunda porción más frecuentemente afectada (35-60\%) y en menor proporción la tercera y cuarta porción (15\% respectivamente) $)^{(14)}$. El compromiso de la primera porción se ha descrito en un $10-14 \%$ de los $\operatorname{casos}^{(14)}$.

En TC el hematoma duodenal se presenta como una zona focal de engrosamiento de la pared intestinal que suele ser excéntrica. Estos pueden llegar a obstruir el lumen duodenal en forma parcial o completa, causando con frecuencia distensión gástrica y vómitos $^{(2,3,7)}$ (Figura 3). Gran parte de los hematomas duodenales pueden ser manejados exitosamente con descompresión nasogástrica y nutrición parenteral ${ }^{(2)}$. La mayoría se resuelven en 10 días, sin embargo, su resolución puede tardar hasta tres semanas ${ }^{(2)}$.

Al igual que los otros segmentos intestinales, las perforaciones duodenales son difíciles de diagnosticar(2). Deben ser sospechadas por la presencia de aire extraluminal, liquido libre en ausencia de daño de órganos sólidos y extravasación del contraste oral(14) (Figura 4).

Intestino delgado Las lesiones se localizan con mayor frecuencia en los puntos de fijación del intestino, siendo la porción proximal del yeyuno (distal al ligamento de Treitz) el segmento más frecuentemente comprometido, seguido por el íleon distal (proximal a la válvula ileocecal $)^{(1,2)}$.

Existen distintos signos en TC de lesiones de asas intestinales y mesenterio, siendo los principales el aire extraluminal, aire libre retroperitoneal, presencia de líquido libre intraperitoneal, infiltración hemática del mesenterio, engrosamiento de la pared intestinal, defecto de la pared intestinal, extravasación de medio de contraste y sangrado activo ${ }^{(8)}$. Estos signos tienen distintas sensibilidades y especificidades ${ }^{(11)}$, siendo los signos más sensibles poco específicos y los signos más específicos poco sensibles ${ }^{(11)}$ (Tabla I). Sin embargo, la presencia de una combinación de estos hallazgos aumenta la probabilidad de una lesión intestinal ${ }^{(11)}$.

Tabla I. Sensibilidad y especificidad en TC de signos de lesión intestinal.

Signo

Líquido libre peritoneal

Infiltración mesentérica

Aire extra luminal

Engrosamiento focal de la parietal

Realce anormal parietal

Extravasación de contraste oral

Discontinuidad pared intestinal
Sensibilidad (\%)

$90-100$

$70-77$

$30-60$

$55-75$

$10-15$

$8-15$

$5-10$
Especificidad (\%)

$15-25$

40 - 90

95

90

90

100

100

Referencia 11 

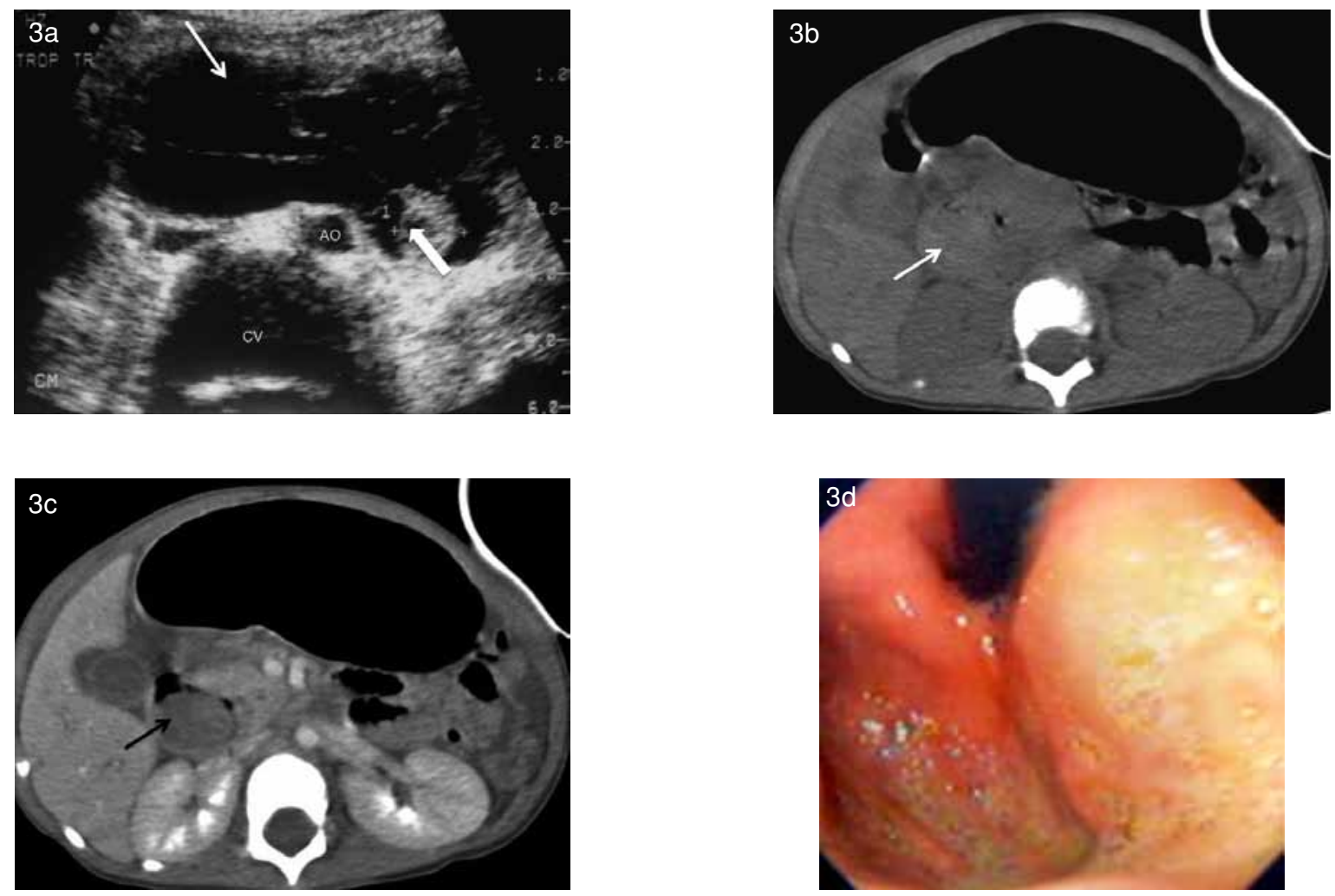

Figura 3. Niño de 2 años, con historia de vómitos y dolor abdominal, sin historia clara de trauma, antecedente de fractura diafisiaria femoral, se sospecha maltrato infantil. a) Ecografía corte axial a nivel del epigastrio, se observa una lesión sólido-quística (flechas blanca gruesa y delgada) de ubicación retroperitoneal por delante de la columna (cv) y la aorta (ao). b) y c) TC corte axial sin y con contraste, se observa que la lesión retroperitoneal que se ubica en la segunda y tercera porción del duodeno es una masa espontáneamente hiperdensa (flecha blanca) que no realza en el estudio contrastado (flecha negra), se trata de un hematoma duodenal que obstruye el lumen duodenal observándose distensión de la cámara gástrica. d) Estudio endoscópico que muestra una compresión extrínseca de la tercera porción del duodeno, que ocluye completamente el lumen.
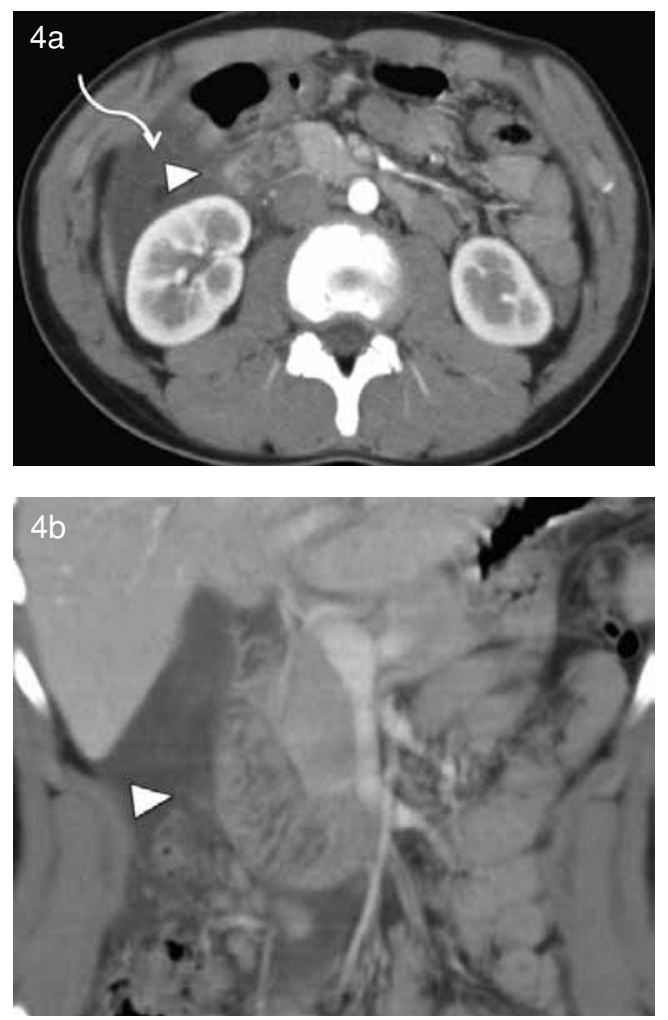

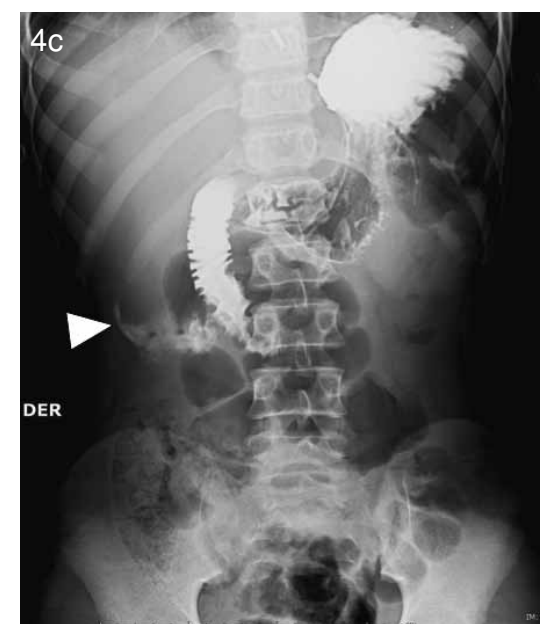

Figura 4. Niño de 13 años, copiloto en colisión vehicular de alta energía. a) y b) TC con contraste en fase venosa, cortes axial y reformateo coronal. Se observa líquido libre (flecha curva) y una zona de mayor densidad cercano a la segunda porción del duodeno (punta de flecha blanca). Se sospecha perforación duodenal. c) Radiografía de abdomen con contraste oral, se confirma la perforación duodenal observándose extravasación de contraste a nivel de la segunda porción del duodeno (punta de flecha blanca). 
Colon: Las lesiones de colon ocurren en el 2 a $5 \%$ de los pacientes con trauma abdominal cerrado ${ }^{(7)}$. El colon transverso es susceptible de lesionarse por compresión contra la columna vertebral ${ }^{(7)}$. El colon sigmoides presenta alto riesgo de perforación por mecanismos de desaceleración. Sin embargo, todos los segmentos de colon (a excepción del recto) son susceptibles
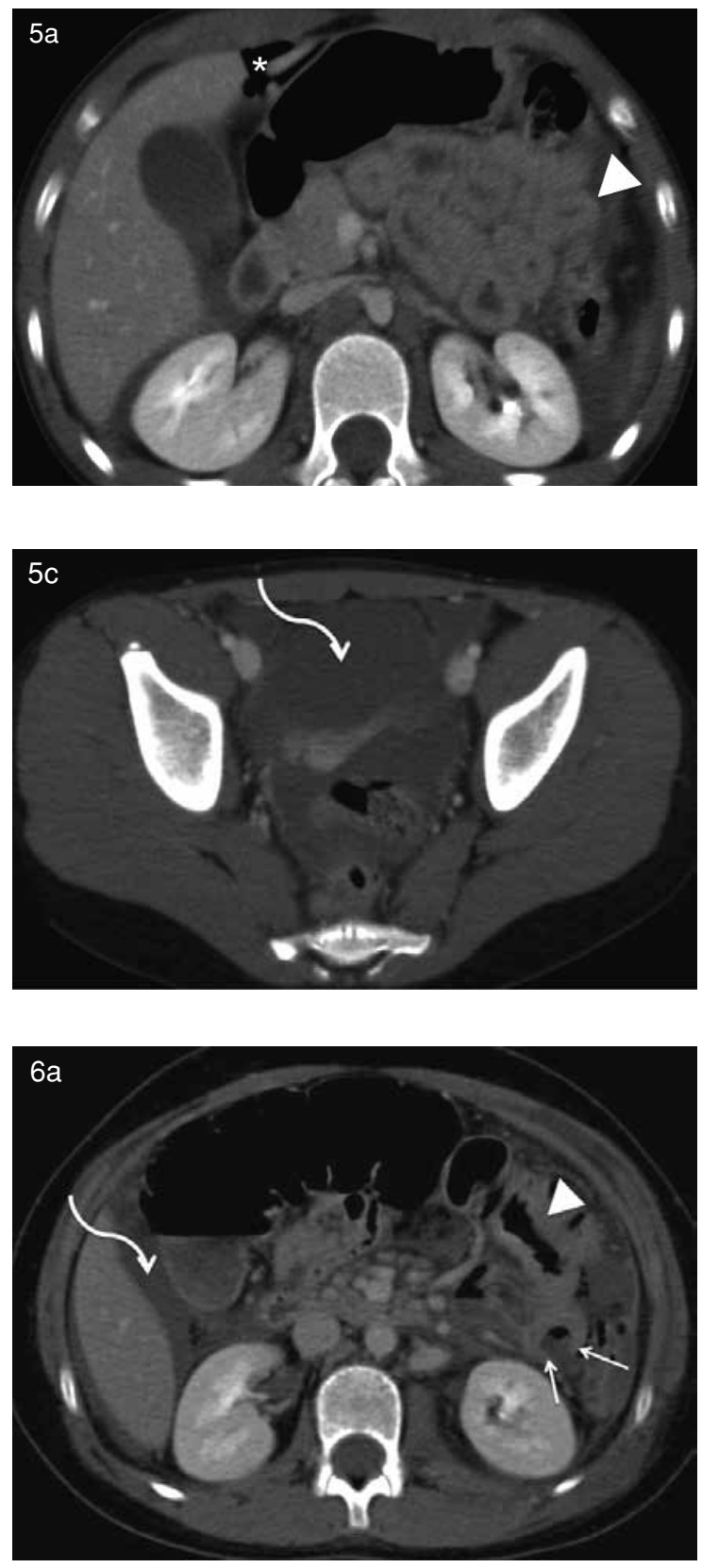

Figura 6. Niña de 10 años. Pasajera trasera en colisión vehicular. a) TC con contraste en fase venosa, corte axial y b) Reformateo coronal. Se observa líquido libre de moderada cuantía (flecha curva blanca), engrosamiento y distensión difusa de asas delgadas (punta de flecha blanca) y un defecto de la pared de un asa yeyunal con borde revertidos (flecha blanca). La laparotomía exploradora confirma una amplia perforación yeyunal. de rotura y avulsión del mesenterio ${ }^{(7)}$.

\section{Hallazgos en TC}

Líquido libre intraperitoneal: La presencia de líquido intraperitoneal sin evidencia de lesión de órganos sólidos es un signo muy sugerente de lesiones gastrointestinal ${ }^{(8)}$. En muchos casos ésta puede ser la única manifestación de injuria intestinal(8) (Figuras 5 y 6 ).

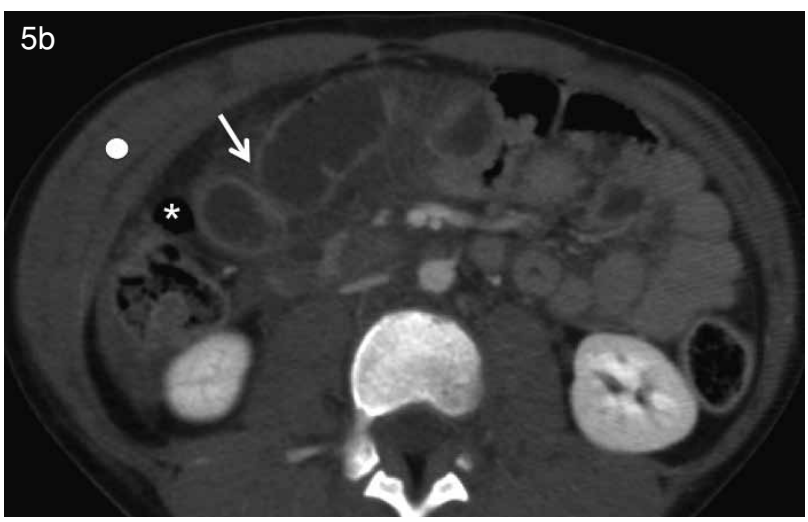

Figura 5. Niña de 9 años. Copiloto en colisión vehicular de alta energía. a), b) y c)TC con contraste en fase venosa, cortes axiales en diferentes niveles. Se observa neumoperitoneo (asterisco), líquido libre en pelvis e interasas (flecha curva blanca), engrosamiento difuso de la pared de las asas intestinales (punta de flecha blanca) y dilatación difusas de asas de íleon distal (flecha blanca) y cambios inflamatorios de tejido adiposo en la fosa ilíaca derecha. En la partes blandas a nivel del flanco derecho hay una zona equimótica de la pared abdominal (círculo). Estos hallazgos en ausencia de lesión de órganos sólidos son sugerentes de una perforación de víscera hueca. Se realizó una laparotomía exploradora confirmando una perforación de íleon distal.

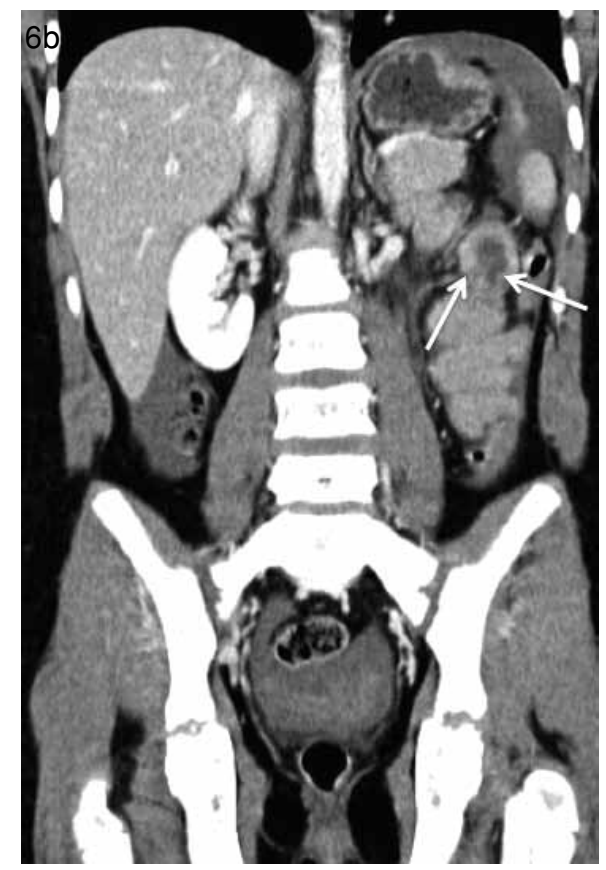


Infiltración del mesenterio y líquido en la raíz del mesenterio: las lesiones intestinales y mesentéricas frecuentemente se asocian a un incremento de la atenuación del mesenterio que son secundarias a la hemorragia e inflamación de éste ${ }^{(8)}$. En líquido a menudo se localiza en la raíz mesentérica adyacente a la aorta y vena cava inferior(8).

Aire libre intraperitoneal: Es un signo altamente sugerente de perforación intestinal, sin embargo, sólo está presente en la mitad de los pacientes con perforación intestinal| ${ }^{(8,11)}$. La revisión de la cavidad abdominal con ventana de pulmón es útil en la detección de aire extraluminal( ${ }^{(8)}$. El aire libre se identifica más frecuente en la región anterior del abdomen cerca del hígado o también puede localizarse contenido en el mesenterio( ${ }^{(8)}$ (Figura 5).

Aire libre retroperitoneal: Indica lesión de órganos retroperitoneales, usualmente el duodeno, pero también puede ser de colon ${ }^{(8)}$.

Engrosamiento de la pared intestinal: El grosor de la pared intestinal normal es de 3-4 mm. Los segmentos engrosados a menudo también presentan mayor realce $^{(8)}$. El engrosamiento de la pared intestinal es limitado inicialmente a un segmento focal del intestino ${ }^{(8)}$, mientras que en el caso de diagnóstico tardío, el engrosamiento es difuso ${ }^{(8)}$ (Figuras 5 y 6 ).

Defecto de la pared intestinal: Este signo tiene una especificidad del $100 \%$, pero una sensibilidad del $5-10 \%{ }^{(11)}$, siendo la visualización del defecto intestinal raro $^{(11)}$ (Figura 6).

Extravasación del medio de contraste oral: Es el signo más específico en perforación intestinal, sin embargo su visualización es infrecuente ${ }^{(8)}$. El contraste extraluminal a menudo es de mayor densidad cerca de la perforación, sin embargo se puede localizar en cualquier lugar del abdomen ${ }^{(8)}$. Los diagnósticos diferencias de líquido hiperdenso en el peritoneo incluye sangre coagulada, sangrado activo y contraste extraluminal extravasado por una rotura del tracto urinario(8).

Sangrado activo: Se puede visualizar como zona focal de mayor atenuación de contraste 45-70 HU, cercana al sitio de sangrado, signo denominado "coágulo centinela"(11).

\section{Conclusión}

La lesión de origen traumático del tracto gastrointestinal es rara, siendo inferior del $1 \%$, sin embargo, su mortalidad es del $20 \%$ en el caso de perforación intestinal. Las manifestaciones clínicas son variadas y dependen de la composición del contenido extrava- sado. Suelen ser secundarias a deceleración brusca y compresión por el cinturón de seguridad.

La tomografía computada es el método de elección en la identificación y cuantificación de las lesiones en trauma abdominal en pacientes hemodinámicamente estables.

\section{Bibliografía}

1. Castellanos A, De Diego E, Fernández I, Trugeda M. Evaluación inicial y tratamiento del traumatismo abdominal infantil. Bol Pediatr 2001; 41: 106-114.

2. Muñiz A. Evaluation And Management Of Pediatric Abdominal Trauma. Ped Emerg Med Pract 2008; 5 (3): 1-32. https:// www.ebmedicine.net/ topics.php?paction =showTopic\&topic_id=132 (Accesado el 11/oct/2013).

3. Sivit J. Imaging Children with Abdominal Trauma. Am J Roentgenol 2009; 192(5): 1179-1189.

4. Nievelstein RA, van Dam IM, van der Molen AJ. Multidetector CT in children: current concepts and dose reduction strategies. Pediatr Radiol 2010; 40(8): 13241344.

5. Linsenmaier U, Krötz M, Häuser H, Rock C, Rieger J, Bohndorf K, et al. Whole-body computed tomography in polytrauma: techniques and management. Eur Radiol 2002; 12(7): 1728-1740.

6. Donnelly LF, Emery KH, Brody AS, Laor T, Gylys-Morin VM, Anton CG, et al. Minimizing radiation dose for pediatric body applications of single-detector helical CT: strategies at a large Children's Hospital. Am J Roentgenol 2006; 176(2): 303-306.

7. Haley MJ. Hollow viscus blunt abdominal trauma in children, UpToDate, Torrey SB (Ed), UpToDate, WeIlesley, MA, 2002. http:// www.uptodate.com/contents/ hollow-viscus-blunt-abdominal-trauma-in-children. (Accesado el 11/oct/2013).

8. Strouse PJ, Close BJ, Marshall KW, Cywes R. CT of bowel and mesenteric trauma in children. Radiographics 1999; 19(5): 1237-1250.

9. Concha A, Rey C, Rodríguez J. Traumatismo Abdominal. Bol Pediatr 2009; 49(207): 58-68.

10. Stanescu AL, Gross JA, Bittle M, Mann FA. Imaging of Blunt Abdominal Trauma. Semin Roentgenol 2006; 41(3): 196-208.

11. Soto JA, Anderson SW. Multidetector CT of blunt abdominal trauma. Radiology 2012; 265(3): 678-693.

12. Dreizin D, Munera F. Blunt polytrauma: evaluation with 64-section whole-body CT angiography. Radiographics 2012; 32(3): 609-631.

13. Tejerina E, Holanda MS, López-Espadas F, Domínguez MJ, Ots E, Díaz J. Gastric rupture from blunt abdominal trauma. Injury 2004; 35(3): 228-231.

14. Pérez L, Mardones R, Domingo J, Espinoza $A$, Ureta $H$, Melo I. Estudio por imágenes del hematoma duodenal en niños, actualización a raíz de tres casos clínicoradiológicos. Acta Med 2010; 4(1): 45-51. 